OPEN ACCESS

Edited by:

Martin Koenneke,

University of Bremen, Germany

Reviewed by:

Francisco Barona-Gómez,

CINVESTAV, Mexico

Jan Kuever

Bremen Institute for Materials Testing,

Germany

*Correspondence:

Praveen Rahi

praveen_rahi22@yahoo.co.in; praveen@nccs.res.in

Specialty section:

This article was submitted to Microbial Physiology and Metabolism,

a section of the journal

Frontiers in Microbiology

Received: 28 January 2016 Accepted: 17 August 2016

Published: 30 August 2016

Citation:

Rahi P, Prakash O and Shouche YS (2016) Matrix-Assisted Laser Desorption/Ionization Time-of-Flight Mass-Spectrometry (MALDI-TOF MS)

Based Microbial Identifications: Challenges and Scopes for Microbial Ecologists. Front. Microbiol. 7:1359. doi: 10.3389/fmicb.2016.01359

\section{Matrix-Assisted Laser Desorption/lonization Time-of-Flight Mass-Spectrometry (MALDI-TOF MS) Based Microbial Identifications: Challenges and Scopes for Microbial Ecologists}

\author{
Praveen Rahi *, Om Prakash and Yogesh S. Shouche \\ Microbial Culture Collection, National Centre for Cell Science, Pune, India
}

Matrix-assisted laser desorption/ionization time-of-flight mass-spectrometry (MALDI-TOF MS) based biotyping is an emerging technique for high-throughput and rapid microbial identification. Due to its relatively higher accuracy, comprehensive database of clinically important microorganisms and low-cost compared to other microbial identification methods, MALDI-TOF MS has started replacing existing practices prevalent in clinical diagnosis. However, applicability of MALDI-TOF MS in the area of microbial ecology research is still limited mainly due to the lack of data on non-clinical microorganisms. Intense research activities on cultivation of microbial diversity by conventional as well as by innovative and high-throughput methods has substantially increased the number of microbial species known today. This important area of research is in urgent need of rapid and reliable method(s) for characterization and de-replication of microorganisms from various ecosystems. MALDI-TOF MS based characterization, in our opinion, appears to be the most suitable technique for such studies. Reliability of MALDI-TOF MS based identification method depends mainly on accuracy and width of reference databases, which need continuous expansion and improvement. In this review, we propose a common strategy to generate MALDI-TOF MS spectral database and advocated its sharing, and also discuss the role of MALDI-TOF MS based high-throughput microbial identification in microbial ecology studies.

Keywords: MALDI-TOF mass spectrometry, microbial identification, spectral database, culturomics, highthroughput identifications

\section{INTRODUCTION}

Microorganisms are ubiquitous in all ecosystems, are intimately associated with environmental sustainability and human development, and perform various ecological functions. Metagenomics and other cultivation-independent studies showed that a major proportion of the world's microbial communities are not yet cultivated and their functions are unknown. Exploiting the information gathered from metagenomics studies, new cultivation techniques are being designed to achieve cultivation of the enormous diversity of the microorganisms present in an ecosystem, 
including dominant and rare species (Vartoukian et al., 2010; Stewart, 2012; Dubourg et al., 2014). Recently a strategy to understand the functional and ecological capacities of microorganisms has been proposed, which include a combination of functional phylogenomics and co-culture-based experiments (Cibrián-Jaramillo and Barona-Gómez, 2016). To meet this goal, high-throughput cultivation techniques are being used, which yield large numbers of microbial isolates. Rapid and accurate characterization of such large number of microorganisms is always a big challenge for any microbiologist. Traditionally, various morphological, physiological and biochemical features were employed for microbial identifications. Application of molecular tools like, small subunit ribosomal RNA gene sequencing, whole genome sequencing, multi-locus sequence typing (MLST), amplified fragment length polymorphism (AFLP), and DNA-DNA hybridization $(\mathrm{DDH})$ enhanced the resolution of microbial identification (Müller et al., 2007; Ragimbeau et al., 2008). At present the polyphasic approach provides the most reliable identification of microorganisms but it is time consuming, expensive, and requires expertise in both conventional as well as in modern microbiological techniques. When dealing with small number of microorganisms, speed, and cost of characterization may not be of considerable importance but are very critical when a larger number of microorganisms are being analyzed.

MALDI-TOF MS has gained popularity as a microbial biotyping tool due to its speed, low-cost, simplicity, and applicability for a wide range of microbes including bacteria, archaea, and fungi especially in clinical set-ups. It is also becoming an increasingly essential technique for microbial characterization and identification in environment microbiology and microbial diversity studies. The ability of this technique to differentiate at the species level has been found useful in describing new species (Koziel et al., 2014; Lang et al., 2015; Patil et al., 2015; Tong et al., 2015). Realizing the importance of MALDI-TOF MS in microbial taxonomy, identification and diversity analysis, the journal Systematic and Applied Microbiology published a special issue on this subject in 2011 (vol. 34). Concept, chemistry, loopholes, and application of the technique have already been discussed earlier by several authors (Seng et al., 2009; Moore and Rosselló-Móra, 2011; Steensels et al., 2011; Welker and Moore, 2011; Murray, 2012; Wieser et al., 2012; Fournier, 2013). However, none of these reviews deals directly with extension and development of MALDI spectral database, and the application of MALDI-TOF MS to microbial ecology. In brief, it requires mixing of microbial cells from a pure colony with the matrix solution, followed by smear preparation on target plate, air drying, loading of plate inside instrument and finally exposing the samples to source of ionization. After ionization, ionized peptides, and proteins travel toward detector in a vacuum tube, and get separated based on their mass to charge ratio $(\mathrm{m} / \mathrm{z})$. Finally, mass spectrum of the strain under study is compared with that of the other strains present in the reference database. The database includes biomarkers spectra of intracellular proteins primarily in the range of 2-20 $\mathrm{kDa}$ (Fenselau and Demirev, 2001; Benagli et al., 2012). Most of the biomarkers detected in MALDI-TOF spectra of intact bacterial cells have a molecular mass below $15 \mathrm{kDa}$ (Ryzhov and Fenselau, 2001; Croxatto et al., 2012; Suarez et al., 2013). Lysis of organisms with organic solvents in acidic conditions favors extraction of basic cytoplasmic proteins. Multiple commercial platforms including Bruker-Biotyper (Bruker Daltonics, Bremen, Germany), Axima Assurance (Shimadzu, Kyoto, Japan), SARAMIS AnagnosTec (AnagnosTec GmbH, Potsdam, Germany), and Andromas (Andromas SAS, Paris, France) have been developed for microbial identification (Risch et al., 2010; Marko et al., 2012). SARAMIS AnagnosTec was acquired by bioMérieux and redeveloped with the name of Vitek-MS (bioMérieux, Marcy L'Etoile, France; Patel, 2013).

In this review, we discuss the importance of reliable database(s) in the MALDI-TOF MS applications in microbial identification, possibilities to improve and expand the limited database(s) with special emphasis on samples of non-clinical origin. The review also provides brief information about its potential applications in microbial ecological studies.

\section{ACCURACY AND RESOLUTION OF MALDI-TOF MS IN MICROBIAL IDENTIFICATION}

MALDI-TOF MS is a rapid and reliable technique for microbial identification as most results obtained using this are similar to that of 16S rRNA gene sequence analysis but at a rapid rate and at a lower cost. This technique is based on fingerprinting analyses of primarily ribosomal proteins, which are synthesized under all growth conditions and are the most abundant cellular proteins (Ryzhov and Fenselau, 2001). Many reports indicated that the technique generated more accurate identification results than the ones based on various phenotypic and biochemical tests conventionally used in microbiological laboratories (Seng et al., 2009; van Veen et al., 2010; Bessède et al., 2011; Bizzini et al., 2011; Carbonnelle et al., 2012). Resolution of certain taxonomic groups, like Bacillus cereus complex, Brukholderia cepacia complex, Escherichia coli and Shigella group, Enterobacter cloacae complex, and Pseudomonas putida complex, still remain a daunting challenge for routine MALDI-TOF MS analysis and 16S rRNA gene sequencing (Pavlovic et al., 2012; Khot and Fisher, 2013; Almuzara et al., 2015). Improved analysis software and new approaches are being used to further increase the taxonomic resolution of MALDI-TOF MS based biotyping, especially for members of such groups and complexes (Fernández-No et al., 2013; Khot and Fisher, 2013; AlMasoud et al., 2014). For example, application of ClinPro Tools software (Bruker Daltonics) was very useful in rapid differentiation of closely related Shigella species from $E$. coli species, which could not have been achieved by methods like $16 \mathrm{~S}$ rRNA gene sequencing and routine MALDITOF MS analysis (Khot and Fisher, 2013). Advantages and limitations of MALDI-TOF MS based microbial characterization to achieve higher taxonomic resolution at different levels have been discussed in details in a recent review (Sandrin et al., 2013). 


\section{ROLE OF DATABASES IN MALDI-TOF MS BASED IDENTIFICATIONS}

Like other automated microbial identification systems (MIDI, Vitek, Biolog etc.) MALDI-TOF MS also relies on a reference database for identification of microorganisms. Although instruments made by different manufacturers follow similar principle, the major differences remains in the procedure and algorithm used in creating their own reference databases (Welker, 2011; Rychert et al., 2013). For example, multiple spectra of a strain were used to generate strain specific "main spectra profile (MSP)" in the Biotyper (Bruker Daltronics) database (Sauer et al., 2008). Vitek MS (BioMerieux), on the other hand, generate a single "Super Spectrum" from spectra of 10 strains belonging to one species and growing them on different media and incubation conditions (Emonet et al.,
2010). Differences in approaches to create separate databases are reflected in the level of accuracy in identification of the same set of microorganisms as presented in Table $\mathbf{1}$.

Until recently, manufacturers of MALDI-TOF MS microbial identification systems targeted mostly clinically important microorganisms, thereby limiting its applications in other areas of microbiological research. Limited uses of MALDITOF MS based identifications in microbial ecology study have been attributed mainly to lack of reference spectra in the databases associated with the instruments, or inability of the spectra to differentiate very similar species (Bizzini et al., 2011; Seng et al., 2013). Therefore, there is a need to augment the existing MALDI-TOF MS databases with spectra of more diverse microorganisms to increase wider application of this technology. Creation of in-house database supplementing the limited commercial database has been

TABLE 1 | Comparative studies on identification of microorganisms using different MALDI-TOF MS platforms and databases from the time point of the published work.

\begin{tabular}{|c|c|c|c|}
\hline Organism (nos.) & $\begin{array}{l}\text { MALDI-TOF MS system and } \\
\text { database }\end{array}$ & Results & References \\
\hline Bacteria from clinical sources (720) & $\begin{array}{l}\text { Bruker Biotyper } \\
\text { Shimadzu MS with Saramis } \\
\text { database }\end{array}$ & $\begin{array}{l}\text { High confidence identifications (94\%) and incorrect } \\
\text { identification }(0.9 \%) \text {. } \\
\text { High confidence identifications ( } 89 \%) \text { and incorrect } \\
\text { identification }(0.5 \%) \text {. }\end{array}$ & Cherkaoui et al., 2010 \\
\hline Bacteria isolated in routine at hospital (317) & $\begin{array}{l}\text { Bruker Biotyper (ver. 2.0) } \\
\text { Axima Assurance system } \\
\text { Shimadzu/SARAMIS (Anagnos Tec } \\
\text { GmbH ver. 2008) }\end{array}$ & $\begin{array}{l}\text { Correct identification to genus level (97.4\%) and } \\
\text { species level (94.9\%). } \\
\text { Correct identification to genus level (97.2\%) and } \\
\text { species level (93.4\%). }\end{array}$ & $\begin{array}{l}\text { Carbonnelle et al., } \\
2012\end{array}$ \\
\hline $\begin{array}{l}\text { Selected bacterial strains with low } \\
\text { discrimination with phenotypic tests, } \\
\text { unusual antimicrobial susceptibility and } \\
\text { fastidious cultures (296) }\end{array}$ & $\begin{array}{l}\text { Bruker Biotyper (ver. 2.0) } \\
\text { Axima Assurance system } \\
\text { Shimadzu/SARAMIS (Anagnos Tec } \\
\text { GmbH ver. 2008) }\end{array}$ & $\begin{array}{l}\text { Correct identification to genus level (94.9\%) and } \\
\text { species level (83.4\%). } \\
\text { Correct identification to genus level (83.8\%) and } \\
\text { species level (65.9\%). }\end{array}$ & $\begin{array}{l}\text { Carbonnelle et al., } \\
2012\end{array}$ \\
\hline
\end{tabular}

Non-fermenting Gram-negative bacilli

isolated from cystic fibrosis (200)
Bruker Biotyper (ver. 3.0)

Vitek MS (SARAMIS ver. 3.62)
Overall identification (97\%), including species level (72.5\%), complex level (5.5\%) and genus (19.0\%), and no identification (3.0\%).

Overall identification (93\%), including species level (80.0\%), complex level (3.5\%), genus (6.0\%) and family (3.5), and no identification (7.0\%).
Bacteria from multiple clinical sources (986) Bruker Biotyper (ver. 3.0)

Vitek MS (IVD v1)

Vitek MS (Saramis database)
Genus and species level (92.7\%), genus level (2.8\%) and no identification (3.2\%). Misidentification to species level (1.2\%) and genus level (0\%). Genus and species level (93.2\%), genus level (0.4\%) and no identification (5.8\%). Misidentification to species level (0.4\%) and genus level (0.2\%). Genus and species level (83.8\%), genus level (3.1\%) and no identification (12.8\%). Misidentification to species level $(0.3 \%)$ and genus level $(0 \%)$.
Marko et al., 2012

Marko et al. 2012 
proven to be highly advantageous for the identification of various microorganisms of clinical and non-clinical origin like Borrelia, Brachyspira, Bradyrhizobium, Leptospira, Nocardia, and Rhizobiaceae (Table 2), which are under-represented in the commercially available databases. It is evident that efforts to create in-house databases are restricted to very specific group of organisms reflecting interest of the laboratories. A boost in the rate of identification is also expected with the inclusion of rare species and recently described species to the database (Lohmann et al., 2013).

TABLE 2 | Expansion and creation of reference spectral database to improve MALDI-TOF MS based identification.

\begin{tabular}{|c|c|c|c|c|c|}
\hline $\begin{array}{l}\text { Taxonomic } \\
\text { group }\end{array}$ & $\begin{array}{l}\text { Strains } \\
\text { (nos.) }\end{array}$ & Growth conditions & $\begin{array}{l}\text { Replicates strain }{ }^{-1} \\
\text { (nos.)* }\end{array}$ & $\begin{array}{l}\text { Spectra MSP-1 } \\
(\text { (nos. })^{\star *}\end{array}$ & References \\
\hline Campylobacter & 09 & \multirow{3}{*}{$\begin{array}{l}\text { Columbia agar containing } 5 \% \text { sheep } \\
\text { blood; microaerobic conditions; incubation } \\
\text { time } 48 \mathrm{~h} \text {; temperature } 42^{\circ} \mathrm{C} \text { under. }\end{array}$} & $8(32)$ & 30 & Alispahic et al., 2009 \\
\hline Arcobacter & 05 & & $8(32)$ & 30 & \\
\hline Helicobacter & 03 & & $8(32)$ & 30 & \\
\hline Yeast & 109 & $\begin{array}{l}\text { SDA medium; incubation time } 2-3 \mathrm{~d} \text {; } \\
\text { temperature } 30^{\circ} \mathrm{C} \text {. }\end{array}$ & - & - & Stevenson et al., 2010 \\
\hline Rhizobiaceae & 56 & $\begin{array}{l}\text { YMA and TY media; incubation time } 24 \mathrm{~h} \text {; } \\
\text { temperature } 28^{\circ} \mathrm{C} \text {. }\end{array}$ & $12(36)$ & 20 & Ferreira et al., 2011 \\
\hline Prevotella & 30 & $\begin{array}{l}\text { Fastidious anaerobic agar with } 5 \% \text { horse } \\
\text { blood; anaerobic conditions; incubation } \\
\text { time } 24-48 \mathrm{~h} \text {; temperature } 35^{\circ} \mathrm{C} \text {. }\end{array}$ & $10(30)$ & 20 & Wybo et al., 2012 \\
\hline Brachyspira & 09 & $\begin{array}{l}\text { BAM and TSA media; anaerobic } \\
\text { conditions; incubation time } 48-72 \mathrm{~h} \text {; } \\
\text { temperature } 28^{\circ} \mathrm{C} \text {. }\end{array}$ & $20(20)$ & 12 & Calderaro et al., 2013 \\
\hline Molds & 294 & $\begin{array}{l}\text { SDA medium; incubation time } 5 \mathrm{~d} \text {; } \\
\text { temperature } 28^{\circ} \mathrm{C} \text {. }\end{array}$ & - & 10 & Lau et al., 2013 \\
\hline Bradyrhizobium & 18 & $\begin{array}{l}\text { YMA and TY media; incubation time } 24 \text {, } \\
48 \text {, and } 72 \mathrm{~h} \text {; temperature } 28^{\circ} \mathrm{C} \text {. }\end{array}$ & $12(36)$ & 20 & $\begin{array}{l}\text { Sánchez-Juanes et al., } \\
2013\end{array}$ \\
\hline Borrelia & 04 & $\begin{array}{l}\text { BSK-II medium with } 6 \% \text { rabbit serum; } \\
\text { incubation time } 7 \mathrm{~d} \text {; temperature } 30^{\circ} \mathrm{C} \text {. }\end{array}$ & $10(40)$ & 25 & Calderaro et al., 2014a \\
\hline Leptospira & 20 & $\begin{array}{l}\text { EMJH medium; incubation time } 7 \mathrm{~d} \text {; } \\
\text { temperature } 30^{\circ} \mathrm{C} \text {. }\end{array}$ & $10(40)$ & 25 & Calderaro et al., 2014b \\
\hline Yeast & 156 & $\begin{array}{l}\text { SDA medium; incubation time } 24-48 \mathrm{~h} \text {; } \\
\text { temperature } 35^{\circ} \mathrm{C} \text {. }\end{array}$ & - & 10 & Carolis et al., 2014 \\
\hline $\begin{array}{l}\text { Staphylococcus } \\
\text { pseudintermedius }\end{array}$ & 40 & Muller Hinton agar with 5\% sheep blood. & $9(27)$ & 27 & Murugaiyan et al., 2014 \\
\hline $\begin{array}{l}\text { Staphylococcus } \\
\text { intermedius }\end{array}$ & 05 & & & & \\
\hline $\begin{array}{l}\text { Staphylococcus } \\
\text { delphini }\end{array}$ & 12 & & & & \\
\hline Brachyspira & 30 & $\begin{array}{l}\text { TSA containing } 10 \% \text { bovine blood; } \\
\text { anaerobic conditions; incubation time } 2-6 \\
\text { d; temperature } 42^{\circ} \mathrm{C} \text {. }\end{array}$ & $12(36)$ & 20 & Warneke et al., 2014 \\
\hline
\end{tabular}

\begin{tabular}{|c|c|c|c|}
\hline Haloarchaea & 32 & NHA medium. & \\
\hline $\begin{array}{l}\text { Halophilic } \\
\text { methanoarchaea }\end{array}$ & 13 & $\begin{array}{l}\text { Defined media with } \mathrm{NaCl} \text { and } \\
\text { trimethylamine. }\end{array}$ & 24 \\
\hline $\begin{array}{l}\text { Halotolerant and } \\
\text { non-halophilic } \\
\text { methanoarchaea }\end{array}$ & 24 & $\begin{array}{l}\text { MB/W medium with different } \\
\text { methanogensis substrates. }\end{array}$ & \\
\hline
\end{tabular}




\section{DEVELOPMENT OF MALDI-TOF MS SPECTRAL DATABASE}

Creating open-source database(s) incorporating reference MALDI-TOF MS spectra of all known species and keep it updated by including newly reported species of microorganisms is a huge task, which requires urgent attention and cooperation of people engaged in this research area. Several researchers have made efforts to expand MALDI-TOF MS spectral database, most of which were done in isolation by creating in-house database. A survey of such independent efforts on in-house database creation revealed number of differences in the procedures of database creation (Table 2). These differences involve mainly growth conditions of microorganisms, replications and minimum number of spectra used to create the mean database spectrum. To develop a universal database the methods for creation and expansion need to be highly standardized. Steps necessary for creating a high quality spectra database are schematically presented in Figure 1. Cultivation of microorganisms as pure culture is prerequisite for MALDI-TOF MS based identification as the contaminated or mixed culture can lead to ambiguous and confusing results. However, researchers used MALDITOF MS-based methods to identify complex model mixture containing multiple bacterial strains by using a biomarker-based strategy (Mahé et al., 2014; Zhang et al., 2015). MALDI-TOF MS based characterization of such mixtures directly from environments and of totally unknown microorganisms, where the variability will be inherently higher, has not been optimized so far. Assigning correct taxonomic designation to the strain is highly important before considering it for MALDI-TOF MS spectral database. This can be achieve either by $16 \mathrm{~S}$ rRNA gene sequencing and/or by using polyphasic approach (including conventional phenotypic and biochemical, and molecular phylogeny).

It has been reported that small variations in growth conditions (i.e., medium composition, $\mathrm{pH}$ and temperature) has practically no or very little impact in MALDI-TOF MS based identification of microbes, which contributes toward higher reproducible results in inter-laboratory comparisons (Valentine et al., 2005). Therefore, in order to create good spectral databases it is preferable to use the growth conditions, which can generate sufficient biomass for analysis. Growth phase may also play a role in protein spectra as with longer incubation microorganisms form resistant structures, but this can be avoided by collecting the biomass during actively growing phase. In certain microorganisms, pigments like melanin, carotenoids, and other photoactive compounds might hinder the quality of the spectra obtained. Buskirk et al. (2011) observed the suppression of peptide and protein ion signals during the acquisition of MALDI-TOF mass spectra in the presence of fungal melanin in MALDI sample deposits. Manipulation of culture conditions to block or reduce pigment synthesis can help in generating acceptable MALDI-TOF fingerprint mass spectra from darkly pigmented microorganisms. Important factor that influences the MALDI-TOF MS spectra is sample-processing methods (Freiwald and Sauer, 2009; Alatoom et al., 2011; Cassagne et al., 2011; Matsuda et al., 2012; Hamprecht et al., 2014; Panda et al., 2015). In a comparative study, yeast identification results obtained by using the Vitek MS (with Biomerieux database) and the Bruker Biotyper exhibited that the former platform was more successful in identification, and this difference was explained by fact that same sample processing method (on-plate $25 \%$ formic acid extraction) was used for characterization and to generate the Vitek MS Saramis, Biomerieux spectra database (Hamprecht et al., 2014). In contrast, the Bruker Biotyper database was created by ethanol-formic acid extraction. Hence, it is vital to define standard sample processing method(s), which can be used with ease for most of the organisms to generate a high quality spectrum for both proposes (identification and database creation). It is also understood that a single sample processing method could not be applied for all types of microorganisms but can be possible for closely related strains or members of same genus. A clear genus trend was observed for Actinomyces, Gemella, Nocardia, and Streptomyces species, for which MALDITOF MS failed to obtain a sufficient protein signals to generate a quality spectrum by formic acid-acetonitrile extraction (Bizzini et al., 2011). Stafsnes et al. (2013) also reported that few isolates out of 400 isolates did not produce good quality MALDITOF MS spectra following extraction with acetonitrile/formic acid/water (50:35:15, v/v) mixture and suggested that the method and solvents used is not sufficient to lyse particular cell wall structures. It is recommended to employ more efficient sample processing methods to get sufficient protein signals. Currently different methods of sample processing, including direct cell, on plate extraction, ethanol-formic acid extraction, trifluoroacetic acid extraction and bead beating extraction are being used at present to acquire good quality MALDI-TOF MS spectra (Box 1). We propose that a good quality spectrum for bacteria should have at least 70-80 peaks and for fungi 30-40 peaks with an average peak intensity of $10^{3}$ arbitrary units or higher. This proposal of accepting lower peak number for fungi is based on the fact that fungal cultures do not liberate proteins as easy as the bacterial cultures does and the MALDI-TOF MS spectra of fungal cultures generally consist of lesser peaks in comparison to bacterial cultures.

We also suggest that the samples should be spotted in triplicates and each spot should be analyzed at least three times generating technical and analytical replicates, to nullify the variations contributed by the technician and the instrument. Ferreira et al. (2011) used 36 independent spectra including biological replicates (two growth media and two incubation temperatures), technical replicates (three spots per sample) and analytical replicates ( 3 independent measurements for each spot) for each bacterial strain to create reference library of 56 type strains belonging to the family Rhizobiaceae. After acquiring multiple good quality MALDI-TOF MS spectra, pre-processing of these newly generated spectra can be done by using software packages available with various MALDI-TOF MS platforms or by using open source software like MALDIquant package and MassSpec Wavelet (Du et al., 2006; Gibb and Strimmer, 2012). After the pre-processing the refined spectra were further aligned to create average spectra and after alignment the peak positions with similar but not identical (i.e., peaks with a variation of $\pm 2 \mathrm{da}$ ) were bin together to make all similar peak mass values 


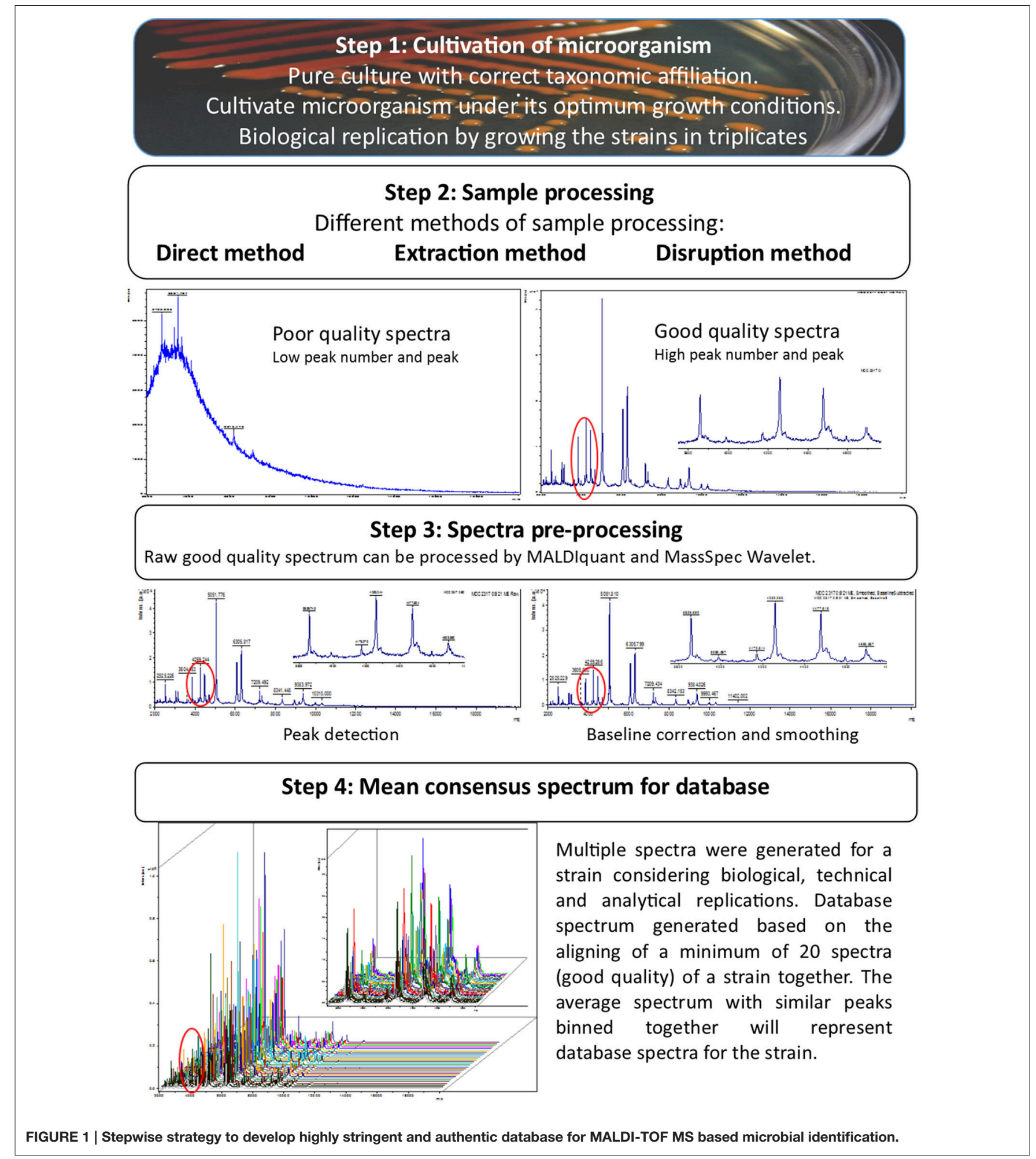

identical. The resulting final average spectra with similar peaks binned together will represent the database spectra for the test strain.

The in-house databases helped researchers to achieve better identification results (Verroken et al., 2010; Ferreira et al.,
2011; Calderaro et al., 2013, 2014a,b; Lau et al., 2013; Sánchez-Juanes et al., 2013; Vávrová et al., 2014; Warneke et al., 2014), but these databases remain inaccessible to other researchers. Development of an open access and universal database incorporating MALDI-TOF MS spectra of as many 


\section{BOX 1 | SAMPLE PROCESSING METHODS FOR MALDI-TOF MS BASED MICROBIAL IDENTIFICATION. \\ 1. Direct method: \\ Direct colony method:}

In this method, bacteria were applied, as thin films on the target plates using sterile toothpicks. The bacterial smear were then left to dry at room temperature for 1 min. Subsequently, $1 \mu$ l of the matrix solution, comprising a saturated $\alpha$-cyano-4-hydrocinnamic acid in $50 \%$ acetonitrile HPLC grade and $2.5 \%$ trifluoroacetic acid, was applied to the samples and co-crystallized with them at room temperature for 10 min (Liu et al., 2007; Freiwald and Sauer, 2009; Matsuda et al., 2012).

\section{Extraction method:}

On plate extraction method:

In this method, each strain was applied and dried on the target plate as in the direct colony method. Following this, $0.5 \mu$ l of $70 \%$ formic acid was mixed with the sample on the plate by pipetting, followed by $0.5 \mu \mathrm{l}$ of acetonitrile, and the resultant mixture was dried at room temperature for approximately 10 min. Finally, $1.5 \mu \mathrm{l}$ of the matrix solution was applied onto the spot as in the direct colony method (Matsuda et al., 2012).

Ethanol-formic acid extraction method:

A loop-full colonies were transferred using a $5 \mu \mathrm{l}$ inoculating loop into $300 \mathrm{ml}$ of distilled water and $900 \mathrm{ml}$ of ethanol. The suspension was pelleted after centrifugation at 12,000 rpm for $2 \mathrm{~min}$, dried, and then reconstituted in 20-80 $\mathrm{ml}$ of $70 \%$ formic acid (select volume based on the pellet size). After incubation for $30 \mathrm{~s}$, equal volume of acetonitrile was added. The suspension was then centrifuged at 12,000 rpm for $2 \mathrm{~min}$. A volume of $1.0 \mu \mathrm{l}$ of the supernatant was applied to spot target plate (Freiwald and Sauer, 2009; Alatoom et al., 2011).

Trifluoroacetic acid extraction method:

Place a loop-full of culture using a $5 \mu \mathrm{l}$ inoculating loop into a tube and add $50 \mu \mathrm{l}$ of $80 \%$ TFA. Suspend the cell mass by pipetting until complete dissolution and denaturation of the sample achieved. Add 3 volumes of double distilled water $(150 \mu \mathrm{l})$ and $200 \mu \mathrm{l}$ of pure acetonitrile and mix by vortexing. Centrifuge at $12,000 \mathrm{rpm}$ at room temperature for $2 \mathrm{~min}$. A volume of $1.0 \mathrm{ml}$ of the supernatant was applied to spot target plate (Freiwald and Sauer, 2009).

\section{Disruption method:}

Physical disruption method:

This procedure is identical to ethanol-formic acid extraction except one additional step that the hydro-alcoholic suspension of sample heated at $95^{\circ} \mathrm{C}$ for $1 \mathrm{~h} \mathrm{before}$ extraction. The step of heating can also be replaced with mechanical lyses by 3 cycles of micro-beads beating (60 s) before extraction as described above in ethanol-formic acid extraction (Cassagne et al., 2011).

Enzymatic lysis method:

Microbial biomass were harvested and washed three times with deionized water. The cell pellet resuspended in $30 \mu$ l of water were digested by adding $10 \mu l$ of 1 $\mathrm{mg} / \mathrm{ml} \mathrm{lysozyme}$ and incubated for $30 \mathrm{~min}$ at $37^{\circ} \mathrm{C}$. Termination of digestion was accomplished by addition of $0.1 \%$ TFA to the pellet (Liu et al., 2007).

microorganisms as possible has been proposed as more appropriate than commercial and individual in-house databases (Mazzeo et al., 2006; Böhme et al., 2012). Initial efforts have already been made in this direction ["FoodBIMS," (http:// bioinformatica.isa.cnr.it/Descr_Bact_Dbase.htm) for 26 species of food borne pathogens (Mazzeo et al., 2006), 200 MALDITOF MS spectra for more than 70 bacterial species with links to the freely available web-based application SPECLUST "SpectraBank" (http://www.usc.es/gl/investigacion/grupos/lhica/ spectrabank/Database.html; Böhme et al., 2012)]. These openaccess databases include results obtained from very few microorganisms and expansion of these databases was not continued. It is imperative that such databases be well curated and be continuously updated. As a first step to achieve this objective the raw data and/or final pooled database files can be submitted as supplementary information along with the publication where the authors reports any expansion or creation of spectral database. Recently, a MALDI-TOF MS database (VibrioBase) was created for fast identification of Vibrio spp. that are potentially pathogenic in humans and all main spectra of this newly created database are freely accessible as btmspfile as supplement with the online article (Erler et al., 2015). It is also expected that MALDI-TOF MS reference spectra created for newly described species will also be made public along with its description as most microbiologist already submit strains with culture collection and sequences with GenBank. Data repositories like Dryad (http://datadryad.org/), which makes data discoverable, freely reusable and citable, can be used as the platform to share newly generated MALDI-TOF MS reference spectra. We hope that more and more researchers will volunteer to make their in-house databases available in public domain.

\section{APPLICATION OF MALDI TOF MS IN MICROBIAL ECOLOGY STUDIES}

Hundreds of millions of microorganisms populate the earth, each year the number of new validly published names of bacteria increases (Parte, 2014). Microbial ecologist and environmental microbiologist have used simulated culture conditions by mimicking the natural environment to cultivate microorganisms previously considered uncultivable (Kaeberlein et al., 2002). Culturomics is a recently coined term and is defined as "an approach allowing an extensive assessment of the microbial composition by high-throughput culture" (Greub, 2012). Though it is not possible to cultivate the whole microbial communities even after using multiple media and growth condition, but several new microorganisms can be cultivated which are till now reported by cultivation-independent methods. Recently, an isolate L21-Fru-AB belonging to novel phylogenetic 
lineage within the Planctomyces-Verrucomicrobia-Chlamydia superphylum, was isolated from hypersaline microbial mats using various cultivation techniques including the use of highly selective defined media as well as more universal complex media (Spring et al., 2015). Based on detailed characterization of strain $\mathrm{L} 21-\mathrm{Fru}-\mathrm{AB}^{\mathrm{T}}$ a novel species and genus Kiritimatiella glycovorans is proposed under the novel phylum Kiritimatiellaeota comprising environmental sequences allocated previously to the Verrucomicrobia subdivision 5 (Spring et al., 2016). The additional advantage of cultivation is that the isolates can be exploited based on their biotechnological potentials. A large number of already known (some unknown as well) microorganisms are generally isolated in bio-prospection studies using, innovative and high-throughput cultivation techniques to culture the dominant, rare, and not-yet-cultivated microbes. Information on the complete or partial characterization of microorganisms play critical role in the selection of potential microbial isolates for further detailed studies. A simple and rapid method of microbial characterization will definitely speed up such research activities. Due to its ability to perform highthroughput identifications and characterization MALDI-TOF MS is the technique of choice in microbial culturomics (Lagier et al., 2012, 2015; Stafsnes et al., 2013; Dubourg et al., 2014). This approach was used to study the microbial diversity of three stool samples, and a total of 340 species of bacteria were identified using MALDI-TOF MS among 32,500 colonies, of which 174 species were recorded for the first time in the human gut (Lagier et al., 2012). In a similar study, 190 bacterial species were identified from 32,000 different colonies isolated from four stool samples, with 9 species described for the first time in the human gut (Dubourg et al., 2014). Application of this technique to identify 2750 isolates of human gut microbiome from 347 individuals (162 with and 185 without diarrhea) in Senegal resulted in $98.8 \%$ successful identifications (Samb-Ba et al., 2014). The remaining 1.2\% (32 isolates, for which MALDITOF MS was not successful) isolates were identified by $16 \mathrm{~S}$ rRNA gene sequencing, which led to detection of two new species.

The limited number of spectral database, which include very few strains of non-clinical origin, results low identification percentage (43-65\%) for microbes isolated from soil, water and other environments (observation in authors' laboratory, data not presented). Similarly, $43 \%$ of bacterial isolates from two waste disposal sites from non-ferrous metal industry were not reliably identified using MALDI TOF MS and fewer than 20\% were identified at species-level (Kopcakova et al., 2014). Despite these limitations, MALDI TOF MS based characterizations have been done for microorganisms from non-clinical sources including, air samples, sewage sludge, biogas plants, ballast water, coastal caves, marine sponges, spinach-processing plant, plant rhizosphere, plant root nodules, wine, and waste disposal sites from non-ferrous metal industry (Dieckmann et al., 2005; Uhlik et al., 2011; Emami et al., 2012; Hausdorf et al., 2013; Stets et al., 2013; Angelakis et al., 2014; Busquets et al., 2014; Kopcakova et al., 2014; Stantscheff et al., 2014; Usbeck et al., 2014). In a comprehensive analysis 5085 isolates of aerobic, heterotrophic and extremely halophilic bacteria and archea from eight solar salterns distributed among different locations in the Spanish Mediterranean, Canary Islands' Atlantic and Chilean Pacific coasts were retrieved combining large-scale cultivation, and identified using MALDI-TOF MS and 16S rRNA gene analysis (Viver et al., 2015). It has been shown that MALDITOF MS is a reliable technique for the identification of diverse microorganisms including both the most commonly encountered aerobic heterotrophic, and the difficult to culture anaerobic, chemotrophic, phototrophic, and extremophilic microorganisms (Krader and Emerson, 2004; Veloo et al., 2011; Biswas and Rolain, 2013; Stantscheff et al., 2014; Vávrová et al., 2014; Shih et al., 2015). MALDI-TOF MS based proteotyping has also been used to eliminate the known species from the unknowns, which resulted into selection of strains of several new species (Dubourg et al., 2014; Samb-Ba et al., 2014; Viver et al., 2015). Tandem study combining MALDI-TOF MS and 16S rRNA gene sequencing of a total of 4243 isolates resulted in to 41 different operational phylogenetic units, of which 22 were regarded as putative new species according to their identity with the closest related type strain sequences (Viver et al., 2015).

In a database-independent approach, MALDI-TOF MS based proteotyping was also be used to recognize identical isolates at specific taxonomic level by clustering them together and selecting representatives of each cluster in order to reduce the number of isolates for subsequent characterization (Dieckmann et al., 2005; Ghyselinck et al., 2011; Stafsnes et al., 2013). De-replication process by this method proved to have higher reproducibility than rep-PCR and considered to be more promising with respect to high-throughput analyses, automation, time, and cost efficiency (Ghyselinck et al., 2011). Stafsnes et al. (2013) also used MALDI-TOF MS as a pre-screening technique for efficient screening of novel pigment producers in a marine bacteria culture collection. A total of 374 isolates from hypersaline sediments of a solar saltern were classified into 25 phenotypic clusters at $52 \%$ similarity based on their whole-cell MALDITOF MS spectra profile (Munoz et al., 2011). The clustering of same species in a MALDI-TOF MS cluster was confirmed by $\mathrm{DDH}$ values above the threshold (70\%) of how a species can be circumscribed and intra-cluster diversity results also correspond to the Random Amplified Polymorphic DNA analysis confirming the accuracy of MALDI-TOF MS clustering (Munoz et al., 2011). A total of 244 bacterial colonies isolated from air samples from Makkah, Saudi Arabia were tested by MALDITOF MS resulted into identification of 202 isolates and the remaining 42 unidentified isolates were further clustered into 10 clusters and 16S rRNA gene sequencing was performed only for one representative strain per cluster (Angelakis et al., 2014).

Since MALDI-TOF MS based characterization is rapid, easy to operate and relatively inexpensive, it may play a bigger role in quality control and validation of microbial strains preserved in large culture collections, institutes and industries. Hence, it is anticipated that in the upcoming era of microbial culturomics MALDI TOF MS based biotyping will play a key role in bringing a revolution in microbial ecology and diversity studies as it did in the field of clinical diagnosis. 


\section{CONCLUSIONS}

MALDI-TOF MS is a powerful, cost effective, rapid, and robust technique for identification of microorganisms (bacteria including anaerobes, fungi including yeast, and archaea). Results obtained by this technique are comparable to, if not better than, those obtained by other time consuming and expensive methods of microbial identification. Inadequate and limited size of database and lack of efficient software capable of enhancing the resolution to differentiate closely related species are some of the current challenges of this technology. Continuous expansion of spectral database with representatives from different groups and/or development of well curated open-access mass spectra database is the need of the hour for wide application of the MALDI-TOF MS based identification in environmental microbiology and ecological studies. Use of common protocols and strategies for development of in-house spectra database will improve the identification efficiency of this technique for microbes. High-throughput microbial identification offered by MALDI-TOF MS has a very important role to play in the era of high-throughput cultivation of microbes. It is expected that, with availability of updated, error free and robust database(s) along

\section{REFERENCES}

Alatoom, A. A., Cunningham, S. A., Ihde, S. M., Mandrekar, J., and Patel, R. (2011). Comparison of direct colony method versus extraction method for identification of gram-positive cocci by use of Bruker Biotyper matrix-assisted laser desorption ionization-time of flight mass spectrometry. J. Clin. Microbiol. 49, 868-2873. doi: 10.1128/JCM.00506-11

Alispahic, M., Hummel, K., Jandreski-Cvetkovic, D., Nöbauer, K., Razzazi-Fazeli, E., Hess, M., et al. (2009). Species-specific identification and differentiation of Arcobacter, Helicobacter and Campylobacter by full-spectral matrix-associated laser desorption/ionization time of flight mass spectrometry analysis. J. Med. Microbiol. 59, 295-301. doi: 10.1099/jmm.0.016576-0

AlMasoud, N., Xu, Y., Nicolaou, N., and Goodacre, R. (2014). Optimization of matrix assisted desorption/ionization time of flight mass spectrometry (MALDI-TOF-MS) for the characterization of Bacillus and Brevibacillus species. Anal. Chim. Acta 840, 49-57. doi: 10.1016/j.aca.2014.06.032

Almuzara, M., Barberis, C., Traglia, G., Famiglietti, A., Ramirez, M. S., and Vay, C. (2015). Evaluation of matrix-assisted laser desorption ionization-time-of-flight mass spectrometry for species identification of nonfermenting gram-negative bacilli. J. Microbiol. Methods 112, 24-27. doi: 10.1016/j.mimet.2015.03.004

Angelakis, E., Yasir, M., Azhar, E. I., Papadioti, A., Bibi, F., Aburizaiza, A. S., et al. (2014). MALDI-TOF mass spectrometry and identification of new bacteria species in air samples from Makkah, Saudi Arabia. BMC Res. Notes 7:892. doi: 10.1186/1756-0500-7-892

Benagli, C., Demarta, A., Caminada, A., Ziegler, D., Petrini, O., and Tonolla, M. (2012). A rapid MALDI-TOF MS identification database at genospecies level for clinical and environmental Aeromonas strains. PLoS ONE 7:e48441. doi: 10.1371/journal.pone.0048441

Bessède, E., Solecki, O., Sifrè, E., Labadi, L., and Mègraud, F. (2011). Identification of Campylobacter species and related organisms by matrix assisted laser desorption ionization-time of flight (MALDI-TOF) mass spectrometry. Clin. Microbiol. Infect. 17, 1735-1739. doi: 10.1111/j.1469-0691.2011.03468.x

Biswas, S., and Rolain, J.-M. (2013). Use of MALDI-TOF mass spectrometry for identification of bacteria that are difficult to culture. J. Microbiol. Methods 92, 14-24. doi: 10.1016/j.mimet.2012.10.014

Bizzini, A., Jaton, K., Romo, D., Bille, J., Prodhom, G., and Greub, G. (2011). Matrix-assisted laser desorption ionization-time of flight mass spectrometry as an alternative to $16 \mathrm{~S}$ rRNA gene sequencing for identification of difficult-to-identify bacterial strains. J. Clin. Microbiol. 49, 693-696. doi: 10.1128/JCM.01463-10 with optimized methods and protocols, this technique will be able to find its extensive use and will prove to be a valuable asset in the field of environmental microbiology, microbial ecology, and taxonomy.

\section{AUTHOR CONTRIBUTIONS}

PR developed the concept and drafted the review article. OP and YS revised it critically for important intellectual content.

\section{ACKNOWLEDGMENTS}

We are very grateful to Dr. Tapan Chakrabarti, Microbial Culture Collection, Pune and Dr. Peter Schumann, Research-Central Services facility, Leibniz-Institute DSMZ-German Collection of Microorganisms and Cell Cultures, Brunswick, Germany for their comments and invaluable suggestions on this manuscript. We also acknowledge the financial support by the Department of Biotechnology (DBT grant no. BT/PR10054/NDB/52/94/2007). Government of India, under the project "Establishment of microbial culture collection." The authors report no conflict of interest.

Böhme, K., Fernández-No, I. C., Barros-Velázquez, J., Gallardo, J. M., Cañas, B., and Calo-Mata, P. (2012). SpectraBank: an open access tool for rapid microbial identification by MALDI-TOF MS fingerprinting. Electrophoresis 33, 2138-2142. doi: 10.1002/elps.201200074

Buskirk, A. D., Hettick, J. M., Chipinda, I., Law, B. F., Siegel, P. D., Slaven, J. E., et al. (2011). Fungal pigments inhibit the matrix-assisted laser desorption/ionization time-of-flight mass spectrometry analysis of darkly pigmented fungi. Anal. Biochem. 411, 122-128. doi: 10.1016/j.ab.2010.11.025

Busquets, A., Fornós, J. J., Zafra, F., Lalucat, J., and Merino, A. (2014). Microbial communities in a coastal cave: Cova des Pas de Vallgornera (Mallorca, Western Mediterranean). Int. J. Speleol. 43, 205-216. doi: 10.5038/1827-806X.43.2.8

Calderaro, A., Gorrini, C., Piccolo, G., Montecchini, S., Buttrini, M., Rossi, S., et al. (2014a). Identification of Borrelia species after creation of an in-house MALDITOF MS database. PLoS ONE 9:e88895. doi: 10.1371/journal.pone.0088895

Calderaro, A., Piccolo, G., Gorrini, C., Montecchini, S., Buttrini, M., Rossi, S., et al. (2014b). Leptospira species and serovars identified by MALDI-TOF mass spectrometry after database implementation. BMC Res. Notes 7:330. doi: 10.1186/1756-0500-7-330

Calderaro, A., Piccolo, G., Montecchini, S., Buttrini, M., Gorrini, C., Rossi, S., et al. (2013). MALDI-TOF MS analysis of human and animal Brachyspira species and benefits of database extension. J. Proteom. 78, 273-280. doi: 10.1016/j.jprot.2012.09.027

Carbonnelle, E., Grohs, P., Jacquier, H., Day, N., Tenza, S., Dewailly, A., et al. (2012). Robustness of two MALDI-TOF mass spectrometry systems for bacterial identification. J. Microbiol. Methods 89, 133-136. doi: 10.1016/j.mimet.2012.03.003

Carolis, E. D., Vella, A., Vaccaro, L., Torelli, R., Posteraro, P., Ricciardi, W., et al. (2014). Development and validation of an in-house database for matrixassisted laser desorption ionization-time of flight mass spectrometry-based yeast identification using a fast protein extraction procedure. J. Clin. Microbiol. 52, 1453-1458. doi: 10.1128/JCM.03355-13

Cassagne, C., Ranque, S., Normand, A.-C., Fourquet, P., Thiebault, S., Planard, C., et al. (2011). Mould routine identification in the clinical laboratory by matrix-assisted laser desorption ionization time-of-flight mass spectrometry. PLoS ONE 6:e28425. doi: 10.1371/journal.pone.0028425

Cherkaoui, A., Hibbs, J., Emonet, S., Tangomo, M., Girard, M., Francois, P., et al. (2010). Comparison of two matrix-assisted laser desorption ionization-time of flight mass spectrometry methods with conventional phenotypic identification for routine identification of bacteria to the species level. J. Clin. Microbiol. 48, 1169-1175. doi: 10.1128/JCM.01881-09 
Cibrián-Jaramillo, A., and Barona-Gómez, F. (2016). Increasing metagenomic resolution of microbiome interactions through functional phylogenomics and bacterial sub-communities. Front. Genet. 7:4. doi: 10.3389/fgene.201 6.00004

Croxatto, A., Prodhom, G., and Greub, G. (2012). Applications of MALDI-TOF mass spectrometry in clinical diagnostic microbiology. FEMS Microbiol. Rev. 36, 380-407. doi: 10.1111/j.1574-6976.2011.00298.x

Dieckmann, R., Graeber, I., Kaesler, I., Szewzyk, U., and von Döhren, H. (2005). Rapid screening and dereplication of bacterial isolates from marine sponges of the Sula Ridge by Intact-Cell-MALDI-TOF mass spectrometry (ICM-MS). Appl. Microbiol. Biotechnol. 67, 539-548. doi: 10.1007/s00253-004-1812-2

Du, P., Kibbe, W. A., and Lin, S. M. (2006). Improved peak detection in mass spectrum by incorporating continuous wavelet transform-based pattern matching. Bioinformatics 22, 2059-2065. doi: 10.1093/bioinformatics/btl355

Dubourg, G., Lagier, J. C., Robert, C., Armougom, F., Hugon, P., Metidji, S., et al. (2014). Culturomics and pyrosequencing evidence of the reduction in gut microbiota diversity in patients with broad-spectrum antibiotics. Int. J. Antimicrob. Agents 44, 117-124. doi: 10.1016/j.ijantimicag.2014.04.020

Emami, K., Askari, V., Ullrich, M., Mohinudeen, K., Anil, A. C., Khandeparker, L., et al. (2012). Characterization of bacteria in ballast water using MALDI-TOF mass spectrometry. PLoS ONE 7:e38515. doi: 10.1371/journal.pone.0038515

Emonet, S., Shah, H. N., Cherkaoui, A., and Schrenzel, J. (2010). Application and use of various mass spectrometry methods in clinical microbiology. Clin. Microbiol. Infect. 16, 1604-1613. doi: 10.1111/j.1469-0691.2010.03368.x

Erler, R., Wichels, A., Heinemeyer, E.-A., Hauk, G., Hippelein, M., Reyes, N. T., et al. (2015). VibrioBase: a MALDI-TOF MS database for fast identification of Vibrio spp. that are potentially pathogenic in humans. Syst. Appl. Microbiol. 38, 16-25. doi: 10.1016/j.syapm.2014.10.009

Fenselau, C., and Demirev, P. A. (2001). Characterization of intact microorganisms by MALDI mass spectrometry. Mass Spectrom. Rev. 20, 157-171. doi: 10.1002/mas.10004

Fernández-No, I. C., Böhme, K., Díaz-Bao, M., Cepeda, M., Barros-Velázquez, J., and Calo-Mata, P. (2013). Characterisation and profiling of Bacillus subtilis, Bacillus cereus and Bacillus licheniformis by MALDI-TOF mass fingerprinting. Food Microbiol. 33, 235-242. doi: 10.1016/j.fm.2012.09.022

Ferreira, L., Sánchez-Juanes, F., García-Fraile, P., Rivas, R., Mateos, P. F., MartínezMolina, E., et al. (2011). MALDI-TOF mass spectrometry is a fast and reliable platform for identification and ecological studies of species from family Rhizobiaceae. PLoS ONE 6:e20223. doi: 10.1371/journal.pone.0020223

Fournier, P. E. (2013). Modern clinical microbiology: new challenges and solutions. Nat. Rev. Microbiol. 11, 574-585. doi: 10.1038/nrmicro3068

Freiwald, A., and Sauer, S. (2009). Phylogenetic classification and identification of bacteria by mass spectrometry. Nat. Protoc. 4, 732-742. doi: 10.1038 /nprot.2009.37

Ghyselinck, J., Hoorde, K. V., Hoste, B., Heylen, K., and Vos, P. D. (2011). Evaluation of MALDI-TOF MS as a tool for high-throughput dereplication. J. Microbiol. Methods 86, 327-336. doi: 10.1016/j.mimet.2011.06.004

Gibb, S., and Strimmer, K. (2012). MALDIquant: a versatile R package for the analysis of mass spectrometry data. Bioinformatics 28, 2270-2271. doi: 10.1093/bioinformatics/bts447

Greub, G. (2012). Culturomics: a new approach to study the human microbiome. Clin. Microbiol. Infect. 18, 1157-1159. doi: 10.1111/1469-0691.12032

Hamprecht, A., Christ, S., Oestreicher, T., Plum, G., Kempf, V. A. J., and Göttig, S. (2014). Performance of two MALDI-TOF MS systems for the identification of yeasts isolated from bloodstream infections and cerebrospinal fluids using a time-saving direct transfer protocol. Med. Microbiol. Immunol. 203, 93-99. doi: 10.1007/s00430-013-0319-9

Hausdorf, L., Mundt, K., Winzer, M., Cordes, C., Fröhling, A., Schlüter, O., et al. (2013). Characterization of the cultivable microbial community in a spinachprocessing plant using MALDI-TOF MS. Food Microbiol. 34, 406-411. doi: 10.1016/j.fm.2012.10.008

Kaeberlein, T., Lewis, K., and Epstein, S. S. (2002). Isolating "uncultivable" microorganisms in pure culture in a simulated natural environment. Science 296, 1127-1129. doi: 10.1126/science.1070633

Khot, P. D., and Fisher, M. A. (2013). Novel approach for differentiating Shigella species and Escherichia coli by matrix-assisted laser desorption ionizationtime of flight mass spectrometry. J. Clin. Microbiol. 51, 3711-3716. doi: 10.1128/JCM.01526-13
Kopcakova, A., Stramova, Z., Kvasnova, S., Godany, A., Perhacova, Z., and Pristas, P. (2014). Need for database extension for reliable identification of bacteria from extreme environments using MALDI TOF mass spectrometry. Chem. Pap. 68, 1435-1442. doi: 10.2478/s11696-014-0612-0

Koziel, M., O’Doherty, P., Vandamme, P., Corcoran, G. D., Sleator, R. D., and Lucey, B. (2014). Campylobacter corcagiensis sp. nov., isolated from faeces of captive lion-tailed macaques (Macaca silenus). Int. J. Sys. Evol. Microbiol. 64, 2878-2883. doi: 10.1099/ijs.0.063867-0

Krader, P., and Emerson, D. (2004). Identification of archaea and some extremophilic bacteria using matrix-assisted laser desorption/ionization timeof-flight (MALDI-TOF) mass spectrometry. Extremophiles 8, 259-268. doi: 10.1007/s00792-004-0382-7

Lagier, J.-C., Armougom, F., Million, M., Hugon, P., Pagnier, I., Robert, C., et al. (2012). Microbial culturomics: paradigm shift in the human gut microbiome study. Clin. Microbiol. Infect. 18, 1185-1193. doi: 10.1111/1469-0691.12023

Lagier, J.-C., Hugon, P., Khelaifia, S., Fournier, P.-E., La Scola, B., and Raoult, D. (2015). The rebirth of culture in microbiology through the example of culturomics to study human gut microbiota. Clin. Microbiol. Rev. 28, 237-264. doi: 10.1128/CMR.00014-14

Lang, E., Schumann, P., Tindall, B. J., Mohr, K. I., and Spröer, C. (2015). Reclassification of Angiococcus disciformis, Cystobacter minus and Cystobacter violaceus as Archangium disciforme comb. nov., Archangium minus comb. nov. and Archangium violaceum comb. nov., unification of the families Archangiaceae and Cystobacteraceae, and emended descriptions of the families Myxococcaceae and Archangiaceae. Int. J. Sys. Evol. Microbiol. 65, 4032-4042. doi: 10.1099/ijsem.0.000533

Lau, A. F., Drake, S. K., Calhoun, L. B., Henderson, C. M., and Zelazny, A. M. (2013). Development of a clinically comprehensive database and a simple procedure for identification of molds from solid media by matrix assisted laser desorption ionization-time of flight mass spectrometry. J. Clin. Microbiol. 51, 828-834. doi: 10.1128/JCM.02852-12

Liu, H., Du, Z., Wang, J., and Yang, R. (2007). Universal sample preparation method for characterization of bacteria by matrix-assisted laser desorption ionization-time of flight mass spectrometry. Appl. Environ. Microbiol. 73, 1899-1907. doi: 10.1128/AEM.02391-06

Lohmann, C., Sabou, M., Moussaoui, W., Prévost, G., Delarbre, J.-M., Candolfi, E., et al. (2013). Comparison between the Biflex III-Biotyper and AximaSARAMIS systems for yeast identification by matrix-assisted laser desorption ionization-time of flight mass spectrometry. J. Clin. Microbiol. 51, 1231-1236. doi: 10.1128/JCM.03268-12

Mahé, P., Arsac, M., Chatellier, S., Monnin, V., Perrot, N., Mailler, S., et al. (2014). Automatic identification of mixed bacterial species fingerprints in a MALDI-TOF mass-spectrum. Bioinformatics 30, 1280-1286. doi: 10.1093/bioinformatics/btu022

Marko, D. C., Saffert, R. T., Cunningham, S. A., Hyman, J., Walsh, J., Arbefeville, S., et al. (2012). Evaluation of the Bruker Biotyper and Vitek MS matrixassisted laser desorption ionization-time of flight mass spectrometry systems for identification of non-fermenting gram-negative bacilli isolated from cultures from cystic fibrosis patients. J. Clin. Microbiol. 50, 2034-2039. doi: 10.1128/JCM.00330-12

Martiny, D., Busson, L., Wybo, I., El Haj, R. A., Dediste, A., and Vandenberg, O. (2012). Comparison of the Microflex LT and Vitek MS systems for routine identification of bacteria by matrix-assisted laser desorption ionizationtime of flight mass spectrometry. J. Clin. Microbiol. 50, 1313-1325. doi: 10.1128/JCM.05971-11

Matsuda, N., Matsuda, M., Notake, S., Yokokawa, H., Kawamura, Y., Hiramatsu, K., et al. (2012). Evaluation of a simple protein extraction method for species identification of clinically relevant Staphylococci by matrix-assisted laser desorption ionization-time of flight mass spectrometry. J. Clin. Microbiol. 50, 3862-3866. doi: 10.1128/JCM.01512-12

Mazzeo, M. F., Sorrentino, A., Gaita, M., Cacace, G., Stasio, M. D., Facchiano, A., et al. (2006). Matrix assisted laser desorption ionization-time of flight mass spectrometry for the discrimination of food-borne microorganisms. Appl. Environ. Microbiol. 72, 1180-1189. doi: 10.1128/AEM.72.2.11 80-1189.2006

Moore, E. R., and Rosselló-Móra, R. (2011). MALDI-TOF MS: a return to phenotyping in microbial identification? Syst. Appl. Microbiol. 34:1. doi: 10.1016/j.syapm.2011.01.001 
Müller, J., Day, J. G., Harding, K., Hepperle, D., Lorenz, M., and Fried, T. (2007). Assessing genetic stability of a range of terrestrial microalgae after cryopreservation using amplified fragment length polymorphism (AFLP). Am. J. Bot. 94, 799-808. doi: 10.3732/ajb.94.5.799

Munoz, R., López-López, A., Urdiain, M., Moore, E. R., and Rosselló-Móra, R. (2011). Evaluation of matrix-assisted laser desorption ionization-time of flight whole cell profiles for assessing the cultivable diversity of aerobic and moderately halophilic prokaryotes thriving in solar saltern sediments. Syst. Appl. Microbiol. 34, 69-75. doi: 10.1016/j.syapm.2010.11.012

Murray, P. R. (2012). What is new in clinical microbiology-microbial identification by MALDI-TOF mass spectrometry: a paper from the 2011 William Beaumont Hospital Symposium on molecular pathology. J. Mol. Diagn. 14, 419-423. doi: 10.1016/j.jmoldx.2012.03.007

Murugaiyan, J., Walther, B., Abou-Elnaga, Y., Brueggemann-Schwarze, S., Vincze, S., Wieler, L. H., et al. (2014). Species differentiation within the Staphylococcus intermedius group using are fined MALDI-TOF MS database. Clin. Microbiol. Infect. 20, 1007-1015. doi: 10.1111/1469-0691.12662

Panda, A., Ghosh, A. K., Mirdha, B. R., Xess, I., Paul, S., Samantaray, J. C., et al. (2015). MALDI-TOF mass spectrometry for rapid identification of clinical fungal isolates based on ribosomal protein biomarkers. J. Microbiol. Methods 109, 93-105. doi: 10.1016/j.mimet.2014.12.014

Parte, A. C. (2014). LPSN-list of prokaryotic names with standing in nomenclature. Nucleic Acids Res. 42, 613-616. doi: 10.1093/nar/gkt1111

Patel, R. (2013). Matrix assisted laser desorption ionization-time of flight mass spectrometry in clinical microbiology. Clin. Infect. Dis. 57, 564-572. doi: $10.1093 / \mathrm{cid} / \mathrm{cit} 247$

Patil, V. S., Salunkhe, R. C., Patil, R. H., Husseneder, C., Shouche, Y. S., and Ramana, V. V. (2015). Enterobacillus tribolii gen. nov., sp. nov., a novel member of the family Enterobacteriaceae, isolated from the gut of a red flour beetle, Tribolium castaneum. Antonie Van Leeuwenhoek. 107, 1207-1216. doi: 10.1007/s10482-015-0412-8

Pavlovic, M., Konrad, R., Iwobi, A. N., Sing, A., Busch, U., and Huber, I. (2012). A dual approach employing MALDI-TOF MS and real-time PCR for fast species identification within the Enterobacter cloacae complex. FEMS Microbiol. Lett. 328, 46-53. doi: 10.1111/j.1574-6968.2011.02479.x

Ragimbeau, C., Schneider, F., Losch, S., Even, J., and Mossong, J. (2008). Multilocus sequence typing, pulsed-field gel electrophoresis, and fla short variable region typing of clonal complexes of Campylobacter jejuni strains of human, bovine, and poultry origins in Luxembourg. Appl. Environ. Microbiol. 74, 7715-7722. doi: 10.1128/AEM.00865-08

Risch, M., Radjenovic, D., Han, J. N., Wydler, M., Nydegger, U., and Risch, L. (2010). Comparison of MALDI TOF with conventional identification of clinically relevant bacteria. Swiss Med. Wkly. 140:w13095. doi: 10.4414/smw.2010.13095

Rychert, J., Burnham, C.-A. D., Bythrow, M., Garner, O. B., Ginocchio, C. C., Jennemann, R., et al. (2013). Multicenter evaluation of the Vitek MS matrixassisted laser desorption ionization-time of flight mass spectrometry system for identification of Gram-positive aerobic bacteria. J. Clin. Microbiol. 51, 2225-2231. doi: 10.1128/JCM.00682-13

Ryzhov, V., and Fenselau, C. (2001). Characterization of the protein subset desorbed by MALDI from whole bacterial cells. Anal. Chem. 73, 746-750. doi: 10.1021/ac0008791

Samb-Ba, B., Mazenot, C., Gassama-Sow, A., Dubourg, G., Richet, H., Hugon, P., et al. (2014). MALDI-TOF identification of the human gut microbiome in people with and without diarrhea in Senegal. PLoS ONE 9:e87419. doi: 10.1371/journal.pone.0087419

Sánchez-Juanes, F., Ferreira, L., de la Vega, P. A., Valverde, A., Barrios, M. L., Rivas, R., et al. (2013). MALDI-TOF mass spectrometry as a tool for differentiation of Bradyrhizobium species: application to the identification of lupinus nodulating strains. Syst. Appl. Microbiol. 36, 565-571. doi: 10.1016/j.syapm.2013.09.003

Sandrin, T. R., Goldstein, J. E., and Schumaker, S. (2013). MALDI-TOF MS profiling of bacteria at strain level: a review. Mass Spectrom. Rev. 32, 188-217. doi: $10.1002 /$ mas. 21359

Sauer, S., Freiwald, A., Maier, T., Kube, M., Reinhardt, R., Kostrzewa, M., et al. (2008). Classification and identification of bacteria by mass spectrometry and computational analysis. PLoS ONE 3:e2843. doi: 10.1371/journal.pone.0002843

Seng, P., Abat, C., Rolain, J. M., Colson, P., Lagier, J. C., Gouriet, F., et al. (2013). Identification of rare pathogenic bacteria in a clinical microbiology laboratory: impact of matrix-assisted laser desorption ionization-time of flight mass spectrometry. J. Clin. Microbiol. 51, 2182-2194. doi: 10.1128/JCM.00 492-13

Seng, P., Drancourt, M., Gouriet, F., La Scola, B., Fournier, P. E., Rolain, J. M., et al. (2009). Ongoing revolution in bacteriology: routine identification of bacteria by matrix-assisted laser desorption ionization time-of flight mass spectrometry. Clin. Infect. Dis. 49, 543-551. doi: 10.1086/600885

Shih, C. J., Chen, S. C., Weng, C. Y., Lai, M. C., and Yang, Y. L. (2015). Rapid identification of haloarchaea and methanoarchaea using the matrix assisted laser desorption/ionization time-of-flight mass spectrometry. Sci Rep. 5:16326. doi: $10.1038 /$ srep 16326

Spring, S., Brinkmann, N., Murrja, M., Spröer, C., Reitner, J., and Klenk, H.-P. (2015). High diversity of culturable prokaryotes in a lithifying hypersaline microbial mat. Geomicrobiol. J. 32, 332-346. doi: 10.1080/01490451.2014.913095

Spring, S., Bunk, B., Sproer, C., Schumann, P., Rohde, M., Tindall, B. J., et al. (2016). Characterization of the first cultured representative of Verrucomicrobia subdivision 5 indicates the proposal of a novel phylum. ISME J. doi: 10.1038/ismej.2016.84. [Epub ahead of print]. Available online at: http://www. nature.com/ismej/journal/vaop/ncurrent/full/ismej201684a.html

Stafsnes, M. H., Dybwad, M., Brunsvik, A., and Bruheim, P. (2013). Large scale MALDI-TOF MS based taxa identification to identify novel pigment producers in a marine bacterial culture collection. Antonie Van Leeuwenhoek 103, $603-$ 615. doi: $10.1007 / \mathrm{s} 10482-012-9844-6$

Stantscheff, R., Kuever, J., Rabenstein, A., Seyfarth, K., Dröge, S., and König, H. (2014). Isolation and differentiation of methanogenic Archaea from mesophilic corn-fed on-farm biogas plants with special emphasis on the genus Methanobacterium. Appl. Microbiol. Biotechnol. 98, 5719-5735. doi: 10.1007/s00253-014-5652-4

Steensels, D., Verhaegen, J., and Lagrou, K. (2011). Matrix-assisted laser desorption ionization-time of flight mass spectrometry for the identification of bacteria and yeasts in a clinical microbiological laboratory: a review. Acta Clin. Belg. 66 , 267-273. doi: 10.2143/ACB.66.4.2062567

Stets, M. I., Pinto., A. S. Jr., Huergo, L. F., de Souza, E. M., Guimarães, V. F., Alves, A. C., et al. (2013). Rapid identification of bacterial isolates from wheat roots by high resolution whole cell MALDI-TOF MS analysis. J. Biotechnol. 165, 167-174. doi: 10.1016/j.jbiotec.2013.04.001

Stevenson, L. G., Drake, S. K., Shea, Y. R., Zelazny, A. M., and Murray, P. R. (2010). Evaluation of matrix-assisted laser desorption/ionization time-of-flight mass spectrometry (MALDI-TOF) for the identification of clinically important yeast species. J. Clin. Microbiol. 48, 3482-3486. doi: 10.1128/JCM.00687-09

Stewart, E. J. (2012). Growing unculturable bacteria. J. Bacteriol. 194, 4151-4160. doi: 10.1128/JB.00345-12

Suarez, S., Ferroni, A., Lotz, A., Jolley, K. A., Guérin, P., Leto, J., et al. (2013). Ribosomal proteins as biomarkers for bacterial identification by mass spectrometry in the clinical microbiology laboratory. J. Microbiol. Methods 94, 390-396. doi: 10.1016/j.mimet.2013.07.021

Tong, S. Y. C., Schaumburg, F., Ellington, M. J., Corander, J., Pichon, B., Leendertz, F., et al. (2015). Novel staphylococcal species that form part of a Staphylococcus aureus-related complex: the nonpigmented Staphylococcus argenteus sp. nov. and the non-human primate-associated Staphylococcus schweitzeri sp. nov. Int. J. Syst. Evol. Microbiol. 65, 15-22. doi: 10.1099/ijs.0.062752-0

Uhlik, O., Strejcek, M., Junkova, P., Sanda, M., Hroudova, M., Vlcek, C., et al. (2011). Matrix-assisted laser desorption ionization (MALDI)-time of flight mass spectrometry- and MALDI biotyper-based identification of cultured biphenyl-metabolizing bacteria from contaminated horseradish rhizosphere soil. Appl. Environ. Microbiol. 77, 6858-6866. doi: 10.1128/AEM. 05465-11

Usbeck, J. C., Wilde, C., Bertrand, D., Behr, J., and Vogel, R. F. (2014). Wine yeast typing by MALDI-TOF MS. Appl. Microbiol. Biotechnol. 98, 3737-3752. doi: 10.1007/s00253-014-5586-x

Valentine, N., Wunschel, S., Wunschel, D., Petersen, C., and Wahl, K. (2005). Effect of culture conditions on microorganism identification by matrix-assisted laser desorption ionization mass spectrometry. Appl. Environ. Microbiol. 71, 58-64. doi: 10.1128/AEM.71.1.58-64.2005

van Veen, S. Q., Claas, E. C., and Kuijper, E. J. (2010). High-throughput identification of bacteria and yeast by matrix-assisted laser desorption ionization-time of flight mass spectrometry in conventional medical 
microbiology laboratories. J. Clin. Microbiol. 48, 900-907. doi: 10.1128/ JCM.02071-09

Vartoukian, S. R., Palmer, R. M., and Wade, W. G. (2010). Strategies for culture of "unculturable" bacteria. FEMS Microbiol. Lett. 309, 1-7. doi: 10.1111/j.15746968.2010.02000.x

Vávrová, A., Matoulková, D., Balážová, T., and Šedo, O. (2014). MALDI-TOF MS analysis of anaerobic bacteria isolated from biofilm-covered surfaces in brewery bottling halls. J. Am. Soc. Brew. Chem. 72, 95-101. doi: 10.1094/ASBCJ-20140324-01

Veloo, A. C. M., Welling, G. W., and Degener, J. E. (2011). The identification of anaerobic bacteria using MALDI-TOF MS. Anaerobe 17, 211-212. doi: 10.1016/j.anaerobe.2011.03.026

Verroken, A., Janssens, M., Berhin, C., Bogaerts, P., Huang, T. D., Wauters, G., et al. (2010). Evaluation of matrix-assisted laser desorption ionization-time of flight mass spectrometry for identification of Nocardia species. J. Clin. Microbiol. 48, 4015-4021. doi: 10.1128/JCM.01234-10

Viver, T., Cifuentes, A., Díaz, S., Rodríguez-Valdecantos, G., Gonzálezb, B., Antón, J., et al. (2015). Diversity of extremely halophilic cultivable prokaryotes in Mediterranean, Atlantic and Pacific solar salterns: evidence that unexplored sites constitute sources of cultivable novelty. Syst. Appl. Microbiol. 38, 266-275. doi: 10.1016/j.syapm.2015.02.002

Warneke, H. L., Kinyon, J. M., Bower, L. P., Burrough, E. R., and Frana, T. S. (2014). Matrix-assisted laser desorption ionization time-of-flight mass spectrometry for rapid identification of Brachyspira species isolated from swine, including the newly described "Brachyspira hampsonii". J. Vet. Diagn. Invest. 26, 635-639. doi: $10.1177 / 1040638714541114$

Welker, M. (2011). Proteomics for routine identification of microorganisms. Proteomics 11, 3143-3153. doi: 10.1002/pmic.201100049
Welker, M., and Moore, E. R. (2011). Applications of whole-cell matrix-assisted laser-desorption/ionization time-of-flight mass spectrometry in systematic microbiology. Syst. Appl. Microbiol. 34, 2-11. doi: 10.1016/j.syapm.2010. 11.013

Wieser, A., Schneider, L., Jung, J., and Schubert, S. (2012). MALDI-TOF MS in microbiological diagnostics-identification of microorganisms and beyond (mini review). Appl. Microbiol. Biotechnol. 93, 965-974. doi: 10.1007/s00253011-3783-4

Wybo, I., Soetens, O., De Bel, A., Echahidi, F., Vancutsem, E., Vandoorslaer, K., et al. (2012). Species identification of clinical Prevotella isolates by matrixassisted laser desorption ionization-time of flight mass spectrometry. J. Clin. Microbiol. 50, 1415-1418. doi: 10.1128/JCM.06326-11

Zhang, L., Smart, S., and Sandrin, T. R. (2015). Biomarker- and similarity coefficient-based approaches to bacterial mixture characterization using matrix-assisted laser desorption ionization time-of-flight mass spectrometry (MALDI-TOF MS). Sci. Rep. 5:15834. doi: 10.1038/srep 15834

Conflict of Interest Statement: The authors declare that the research was conducted in the absence of any commercial or financial relationships that could be construed as a potential conflict of interest.

Copyright (c) 2016 Rahi, Prakash and Shouche. This is an open-access article distributed under the terms of the Creative Commons Attribution License (CC BY). The use, distribution or reproduction in other forums is permitted, provided the original author(s) or licensor are credited and that the original publication in this journal is cited, in accordance with accepted academic practice. No use, distribution or reproduction is permitted which does not comply with these terms. 